\title{
RESENHA
}

\section{Docência patológica existe?}

\author{
Nádia Kienen \\ Universidade do Sul de Santa Catarina - UNISUL \\ Sílvio Paulo Botomé \\ Universidade Federal de Santa Catarina - UFSC
}

Livro: Esteve, J. M. (1999). O mal-estar docente: a sala de aula e a saúde dos professores. Bauru: Editora da Universidade do Sagrado Coração.

A saúde do professor depende da sala de aula. Será? José Manuel Esteve, um experiente profissional espanhol da área da Educação, examina essa possibilidade e, com sua experiência de professor em vários países da Europa, avalia o trabalho que realiza como estudioso do fenômeno do "mal-estar docente". Seu livro é uma excelente leitura para educadores, professores e cientistas que estudam tanto os fenômenos educacionais como aqueles relacionados à saúde na sociedade ou nas organizações, nos processos de trabalho ou nas relações entre as pessoas. Um texto de alto nível merece uma leitura cuidadosa, e esse é o caso do livro "O mal-estar docente" de José Manuel Esteve, que chega ao Brasil com tradução de Durley de Carvalho Cavicchia, publicado pela Editora da Universidade do Sagrado Coração (Bauru, SP), em 1999.

A partir, principalmente, das décadas de 1960 e 1970, ocorreram transformações sociais, políticas, econômicas e culturais que afetaram diretamente a vida das pessoas. Nesse sentido, não é socialmente correto, nem ético ou justo desenvolver um projeto de ensino que não faça jus às novas exigências sociais como, por exemplo, manter um ensino de elite para uma população que nada tem a ver com valores elitistas. Não é objetivo da educação repassar ou, meramente, treinar habilidades técnicas. Cabe ao trabalho educativo, como examinaram Postman e Weingartner (1972), desenvolver um novo tipo de pessoa, com capacidade indagadora, flexível, criadora, tolerante, inovadora, capaz de enfrentar incertezas e ambigüidades de forma orientada. Uma pessoa que seja capaz de formular significados novos e viáveis para lidar com as mudanças no meio, principalmente aquelas que ameaçam a sobrevivência individual e coletiva. É a educação que torna possível decidir o que as pessoas deverão ser capazes de fazer no futuro delineando, assim, a sociedade que existirá nos próximos anos. É por meio dela que são construídas ou ao menos deveriam sê-la - grande parte das capacidades técnicas, científicas, culturais e também éticas que constituirão o potencial das pessoas para lidar com a realidade social. Por tudo isso, parece necessária uma revisão dos referenciais, dos objetivos e do tipo de ser humano a ser formado pelo trabalho educativo. Uma definição que precisa vir da sociedade e dos professores que realizam o trabalho de construção da capacidade das pessoas para viverem nessa sociedade.

No exame do "mal-estar docente" parece útil que alguém seja capaz de: $1^{\circ}$ ) situar e conceituar "malestar docente"; $2^{\circ}$ ) explicitar os indicadores desse tipo de fenômeno; $3^{\circ}$ ) compreender as relações entre tais indicadores; $4^{\circ}$ ) indicar possibilidades para diminuir os efeitos negativos do ciclo degenerativo da eficácia docente. Esses são os quatro objetivos do autor nessa obra sobre o fenômeno do "mal-estar" funcional no exercício do trabalho de educador.

Para compreender o que acontece com as condições de saúde dos docentes, é necessário utilizar um enfoque multidisciplinar, na medida em que existem muitos fatores que afetam tais condições. Sendo assim, variáveis sociais, políticas, culturais, das relações estabelecidas no ambiente escolar, além de variáveis mais especificamente relacionadas aos próprios docentes, tais como sua experiência, seu status socioeconômico, sexo, tipo de instituição em que ensinam etc., precisam ser consideradas para que seja possível caracterizar amplamente as condições de saúde dos professores. Não levar em conta essas variáveis significa estudar o fenômeno de forma parcial e fragmentada. Assim, o uso de abordagens muito genéricas, que consideram apenas variáveis relacionadas ao contexto socioeconômico, desconsiderando aquelas relacionadas às condições específicas de cada docente, falsifica ou compromete a compreensão do "mal-estar docente".

Analisar as condições de saúde dos professores exige que seja explicitada, primeiramente, a concepção de saúde que será adotada. Esteve considera nessa obra que as pessoas têm suas condições de saúde alteradas quando já não têm mais capacidade para trabalhar ou estão muito próximas a isso. Considerar a saúde como um processo no qual podem ocorrer graus de alterações de conforto e de 
segurança das pessoas amplia a percepção do que pode ou não ser alterado como "condições de saúde docente" (ver Chaves, 1980; Rebelatto \& Botomé, 1999). A própria falta de reconhecimento ou a dificuldade em relacionar-se com os colegas ou os alunos, por exemplo, pode produzir determinadas sensações e percepções nos docentes que, muitas vezes, podem ser consideradas como uma forma de "adoecimento", na medida em que diminui a situação de conforto e de bem-estar. Considerar apenas os casos nos quais o afastamento do trabalho já ocorreu parece não dar conta de todo o fenômeno do "malestar", na medida em que desconsidera as várias alterações que, geralmente, antecedem a impossibilidade para o trabalho propriamente dito.

Contextualizar o trabalho docente é estritamente essencial para que seja possível compreender suas condições de saúde. Um aspecto do atual exercício docente está relacionado à defasagem de sua formação profissional, pois ela ainda está calcada em uma imagem do "bom professor". Uma imagem associada, basicamente, às características de personalidade que o indivíduo deve apresentar para praticar "uma boa docência", como se fosse responsabilidade única do professor o sucesso ou o fracasso na educação. Essa idealização do "bom professor" é mistificação, na medida em que é necessário considerar vários fenômenos contextuais (sociais, econômicos, políticos, do próprio ambiente de trabalho, das condições possibilitadas para o exercício da docência etc.), além das características pessoais do professor, para que o exercício docente possa ser efetivo.

A formação do professor precisa desenvolver competências que auxiliem os docentes a reverem suas atuações quando constatam um fracasso na relação com os alunos. Essa revisão pode ocorrer por meio do estudo da realidade em que os alunos vão viver, com o fim de o ensino responder, pela formação dos alunos, às necessidades e exigências do meio. Quando isso ocorre, há um deslocamento da concepção de "problemas na sua personalidade" para uma concepção mais sistêmica, na qual são considerados aspectos outros como a inadequação de suas atuações ou de estratégias utilizadas para ensinar, para administrar o ensino, por exemplo.

Outro aspecto a ser considerado como influência no trabalho do educador é o pouco reconhecimento de sua profissão, que surge por meio de uma representação decadente do trabalho docente, que transparece em expressões como "escolhe ser professor quem não consegue ser outra coisa"; bem como dos baixos salários, os quais têm estreita relação com um baixo status social que, por sua vez, influencia os níveis salariais que são oferecidos aos docentes. É uma relação circular na qual o status de professor condiciona seu salário, e ao mesmo tempo, tal salário condiciona um nível "pra lá de baixo" do papel de docente na sociedade. Nesse sentido, como se não bastassem a formação profissional defasada e a falta de reconhecimento da profissão de educador, ocorre um aumento das exigências e da responsabilidade com uma inaceitável contrapartida: diminuição dos salários. Sim, os professores têm a incumbência de ampliar cada vez mais seu campo de atuação, de desenvolver cada vez mais competências em seus alunos para que eles possam lidar com a atual realidade social e, como consequiência, recebem salários minguados e um reconhecimento fatalista relacionado a uma visão de que só é professor quem não foi capaz de conseguir desenvolver outra profissão. Lamentável para o professor, para a educação e para a sociedade.

Com tudo isso, também aumentou nas escolas a ocorrência de atos de violência de diferentes tipos por parte dos alunos, produzindo medo e insegurança nos docentes. Apesar de a probabilidade de "ataques reais de violência" ser baixa, a maioria experimenta sensações de medo pelo fato de saber da existência e da possibilidade de ocorrência de violências que podem, algum dia, ser direcionadas a eles. Não só a violência física, mas as várias manifestações de descaso, desconsideração, desprezo e desvalorização, pesam muito na condição de docência no sistema educacional.

"Burnout", absenteísmo, inibição (corte do envolvimento pessoal no trabalho) e adoção da rotina como referencial de qualidade (ou do que "é correto") são as consequiências mais comuns do mal-estar docente. Esteve indica que, do ponto de vista estatístico, o absenteísmo, a rotina e a inibição são muito mais comuns do que alterações na saúde mental propriamente dita. Ele estudou alguns milhares de professores por um período de sete anos, utilizando as licenças oficiais por doença que constavam nos arquivos da Inspeção Médica da Delegação de Educação e Ciência em Málaga. A partir desses estudos, indicou dados relacionados aos tipos de licenças mais comuns, a características de gênero e idade das populações mais afetadas, bem como ao número médio de dias de afastamento em cada ano, desde 1982 até 1989. Observou que as mulheres são mais afetadas do que os homens; a média de idade não variou muito, aproximando-se dos 40 anos; a duração média das licenças diminuiu, indo de 41 dias no período de 1982 a 1983 para 26,45 dias no período de 1988 a 1989. Os motivos de licença mais freqüentes foram: $1^{\circ}$ ) traumatologia; $2^{\circ}$ ) otorrinolaringologia; $3^{\circ}$ ) psiquiatria.

No capítulo final de sua obra, o autor desenvolve um modelo compreensivo do mal-estar docente que vai além da incidência das dificuldades objetivas (como a inadequação da formação, falta de reconhecimento social etc.) sobre a interação entre professor e aluno e sobre as possibilidades de atuação do próprio docente. $\mathrm{O}$ autor considera, basicamente, duas possibilidades para o professor: 1) aprender por tentativa e erro e 2) fracassar. No caso de o professor aprender por tentativa e erro, existem duas possibilidades: a) o professor pode possuir os recursos adequados para lidar com a situação de docência ou b) pode carecer deles, mas envolver-se no trabalho independentemente disso. No caso do professor que possui os recursos adequados é possível falar em "auto-realização do professor por meio do magistério". Já no caso do professor que não possui os recursos, mas se envolve no trabalho mesmo assim, há 
tensões e dificuldades que se acumulam, porém, o professor mantém seu esforço e sua motivação. Ele trabalhará cada vez com mais tensão, pois tem dificuldades e, muitas vezes, não consegue eliminar os problemas. Nestes casos são comuns estados de ansiedade generalizada (Seligman, 1977; VasquesMenezes \& Soratto, 2000). São fortes candidatos ao "burnout". Eles se culpam por seu fracasso no magistério.

Na obra de Esteve é considerada a natureza social do "mal-estar docente", deslocando-o de uma compreensão internalista, na qual o sucesso ou o fracasso do exercício profissional dependem exclusivamente do indivíduo, para uma compreensão do fenômeno como sendo multideterminado e instável. Um fenômeno que faz parte de um sistema complexo de relações entre múltiplas variáveis, não só da personalidade do indivíduo, mas do próprio contexto (tanto microssocial, relacionado à realidade da escola onde atua; quanto macrossocial, relacionado ao contexto social, econômico e cultural da época). Certamente os professores têm sua parte de responsabilidade no que lhes acontece no ambiente de trabalho, na medida em que, apesar desses fatores, têm atuações diferentes, conforme suas aprendizagens e sua história de vida. O exame de Esteve, porém, chama a atenção para a necessidade de que sejam revistos os referenciais que serão desenvolvidos nos educandos, bem como a formação dos próprios professores responsáveis pela realização desse desenvolvimento. Os professores precisam ter competências específicas bem desenvolvidas para lidar com a educação. Sua formação precisa desenvolver competências que estejam relacionadas não somente a conhecimentos e técnicas, mas à própria capacidade de lidar com as características das instituições de ensino e das exigências que os ambientes de vida de seus alunos vão lhes exigir como profissionais e agentes sociais depois que terminarem sua formação e forem declarados como "sendo aptos". Para formar professores é preciso, inicialmente, ter clareza acerca do que eles devem estar "aptos a fazer" para que seja possível capacitá-los a apresentarem essas aptidões na atuação social. E essa formação pode estar longe disso, levando os docentes a um "adoecimento" cada vez mais perceptível a evidenciarse nas consequiências das condições de trabalho dos docentes contemporâneos.

\section{REFERÊNCIAS}

Chaves, M. M. (1980). Saúde \& sistemas (3. ed.). Rio de Janeiro: Fundação Getúlio Vargas.

Esteve, J. M. (1999). O mal-estar docente: a sala de aula e a saúde dos professores. Bauru: Editora da Universidade do Sagrado Coração.

Postman, N. \& Weingartner, C. (1972). Contestação: nova fórmula de ensino (2. ed.). Rio de Janeiro: Expressão e Cultura.

Rebelatto, J. R. \& Botomé, S. P. (1999). Fisioterapia no Brasil. (2. ed.). São Paulo: Manole.

Vasques-Menezes, I. \& Soratto, L. (2000). Burnout e suporte social. Em: W. Codo (Org.), Educação: carinho e trabalho (pp. 267-271) (2. ed.). Petrópolis: Vozes. 


\section{Sobre os autores da resenha}

Nádia Kienen: Mestre pelo Programa de Pós-Graduação em Psicologia pela Universidade Federal de Santa Catarina - Professora do Curso de Psicologia da Universidade do Sul de Santa Catarina - UNISUL - Endereço para correspondência: nadiakienen@unisul.br.

Sílvio Paulo Botomé: Professor Doutor do Departamento de Psicologia e do Programa de Pós-Gradução em Psicologia da Universidade Federal de Santa Catarina - UFSC - Endereço para correspondência: botome@cfh.ufsc.br. 